\title{
The Relationship between Insulin Resistance and Polymorphisms of the Endothelial Nitric Oxide Synthase Gene in Patients with Coronary Artery Disease
}

\author{
Toru Yoshimura ${ }^{1}$, Akitaka Hisatomi ${ }^{1}$, Susumu Kajihara1, Tsutomu Yasutake ${ }^{1}$, Youko Ogawa ${ }^{1}$, \\ Toshihiko Mizuta', Iwata Ozaki², Toshinori Utsunomiya ${ }^{3}$, and Kyosuke Yamamoto ${ }^{1}$ \\ ${ }^{1}$ Division of Endocrinology and Metabolism, Department of Internal Medicine, Saga Medical School, Saga, Japan. \\ ${ }^{2}$ Health Administration Center, Saga Medical School, Saga, Japan. \\ ${ }^{3}$ Division of Cardiology, Department of Internal Medicine, Saga Medical School, Saga, Japan.
}

\begin{abstract}
Nitric oxide (NO) regulates endothelial function and is believed to prevent atherogenesis. In endothelial cells, endothelial nitric oxide synthase (eNOS) is expressed constitutively, and regulates NO synthesis. A mutation of the eNOS gene has been associated with the development of coronary artery disease (CAD). The development of CAD is also influenced by insulin resistance, and recent studies suggest that NO might affect cellular insulin activity. We investigated the association between eNOS polymorphisms and insulin resistance in patients with CAD. We screened 45 patients with a history of myocardial infarction (MI), angina pectoris (AP), or coronary spasm. Genotypes were determined by polymerase chain reaction-restriction fragment-length polymorphism analysis. We examined two polymorphisms of the eNOS gene (The $\mathrm{T}^{-786} \rightarrow \mathrm{C}$ variant and the missense Glu298Asp variant). Insulin resistance was measured by determining the plasma immunoreactive insulin concentration at the $120 \mathrm{~min}$ time point (IRI 120) of a $75 \mathrm{~g}$ oral glucose tolerance test. The IRI 120 of the $\mathrm{T}^{-786} \rightarrow \mathrm{C}$ variant group was higher than that for the control group $(p<0.05)$. This finding demonstrates that the $\mathrm{T}^{-786} \rightarrow \mathrm{C}$ mutation in the eNOS gene decreases insulin sensitivity. J Atheroscler Thromb, 2003; 10: 43-47.
\end{abstract}

Key words: Myocardial infarction, Missense, Genetic variants, Nitric oxide

\section{Introduction}

Nitric oxide (NO) is synthesized from L-arginine by endothelial NO synthase (eNOS), and is responsible for maintaining basal vascular tone. In addition to relaxing vascular smooth muscle cells, NO inhibits platelet and leukocyte adhesion to vascular endothelium, inhibits vascular smooth muscle cell migration and growth, and limits the oxidation of atherogenic low density lipoprotein [1-5]. Experiments with eNOS knockout mice have shown decreased NO synthesis and insulin resistance [6].

Address for correspondence: Toru Yoshimura, MD, Division of Endocrinology and Metabolism, Department of Internal Medicine, Saga Medical School, 5-1-1 Nabeshima, Saga 849-8501, Japan.

E-mail: g9910@post.saga-med.ac.jp

Received August 26, 2002.

Accepted for publication October 30, 2002.
Recently, several polymorphisms of the eNOS gene have been described in humans. One of the most extensively studied mutations is the missense Glu298Asp variant. This is a $\mathrm{G}$ to $\mathrm{T}$ conversion of nucleotide 894 in exon 7 . This common variant has been associated with a higher incidence of myocardial infarction (MI), coronary spasm, and hypertension [7-10]. The other mutation is a $\mathrm{T}^{-786} \rightarrow \mathrm{C}$ variant. This mutation occurs in the 5'-flanking region of the eNOS gene, and is associated with coronary spasm, MI, and cerebral circulation [11, 13].

Insulin resistance has also been suggested to contribute to the pathogenesis of coronary artery disease (CAD) $[14,15]$. However, no other investigators have described the relationship between eNOS gene polymorphisms and insulin resistance. To further elucidate the role of mutations of the eNOS gene in insulin resistance in patients with $C A D$, we examined the relationship between eNOS 
polymorphisms $\left(\mathrm{T}^{-786} \rightarrow \mathrm{C}\right.$ variant, missense Glu298Asp variant) and insulin resistance in a Japanese population. Insulin resistance was measured using the plasma immunoreactive insulin concentration at the 120 min time point (IRI 120) of a $75 \mathrm{~g}$ oral glucose tolerance test. We found an effect of eNOS gene variations on insulin resistance.

\section{Subjects and Methods}

\section{Study patients}

The study included 45 patients with coronary artery disease [28 with myocardial infarction (MI), 11 with angina pectoris (AP), 6 with coronary spasm] admitted to Saga Medical College hospital from September 1998 to November 1999 (Table 1). Myocardial infarction was diagnosed by the presence of typical symptoms, electrocardiographic changes, serum creatine kinase-MB isozyme (CK-MB) elevations, and cardiac catheterization. Angina pectoris was diagnosed by symptoms, electrocardiographic changes, and angiographic evidence of coronary artery stenosis. Coronary spasm was angiographically documented during cardiac catheterization. We excluded patients taking medications that influence insulin sensitivity, $\beta$-blockers, or troglitazone. The study was approved by our institutional review board, and informed consent was obtained from each patient before inclusion in the study.

\section{Identification of eNOS gene variants by polymerase chain reaction-restriction fragment-length polymor- phism (PCR-RFLP)}

To identify possible mutations of the eNOS gene, we performed PCR-RFLP. Genomic DNA was prepared from blood leukocytes by established methods.

eNOS $-786 \mathrm{~T} \rightarrow \mathrm{C}$

A set of primers was designed to amplify the 159 base pair (bp) fragment encompassing the mutation $-786 \mathrm{~T} \rightarrow \mathrm{C}$ (the sense and antisense primers were 5'-TGAAGTGCCT GGAGAGTGCT-3', and 5'-ACGCACGCTTCCCGGGTCC GCAGGTCAGCA-3', respectively). The PCR fragments were digested with the restriction enzyme Hae III and separated by agarose gel electrophoresis.

eNOS $894 \mathrm{G} \rightarrow \mathrm{T}$

A specific set of primers and restriction enzyme were used as described previously [16].

\section{Oral glucose tolerance test (OGTT)}

After a $12 \mathrm{~h}$ overnight fast, patients underwent a $75 \mathrm{~g}$ OGTT after a $12 \mathrm{~h}$ overnight fast.

\section{Statistical analysis}

Statistical analysis was performed using the MannWhitney U test. StatView J 4.5 software (Abacus Concepts, CA) was used for the analysis. A value of $p<0.05$ was considered statistically significant.
Table 1. Clinical characteristics of study patients

\begin{tabular}{lc}
\hline Patients with CAD $(\mathrm{n}=45)$ & \\
\hline Age $(\mathrm{y})$ & $62.6 \pm 9.8$ \\
Male/female & $33 / 12$ \\
$\mathrm{Ml} / \mathrm{AP} / \mathrm{spasm}$ & $28 / 11 / 6$ \\
$\mathrm{DM} / \mathrm{IGT} / \mathrm{NGT}$ & $12 / 13 / 20$ \\
$\mathrm{FBG}(\mathrm{mg} / \mathrm{dl})$ & $101 \pm 23$ \\
$\mathrm{FIRl}(\mu / \mathrm{ml})$ & $8.1 \pm 3.7$ \\
$\mathrm{HbA}$ & $5.7 \pm 1.2$ \\
\hline
\end{tabular}

CAD, coronary artery disease; MI, myocardial infarction; AP, angina pectoris; DM, diabetes mellitus; IGT, impaired glucose tolerance; NGT, normal glucose tolerance; FBG, fasting blood glucose; FIRI, fasting immunoreactive insulin. Data are reported as the mean \pm SD.

\section{Results}

\section{Screening for the $\mathrm{T}^{-786} \rightarrow \mathrm{C}$ variant in the 5'-flanking} region of the eNOS gene.

Fig. 1A shows a representative agarose gel loaded with PCR products after digestion with Hae III from 3 different patients. The eNOS/TT, TC, and CC genotypes were present in $38(84.4 \%), 7$ (15.6\%), and $0(0 \%)$ of 45 patients with $C A D$, respectively.

\section{Screening for the missense Glu298Asp variant of the eNOS gene.}

Fig. 1B shows a representative agarose gel loaded with PCR products after digestion with Mbo I from 3 different patients. The eNOS/GG, GT, and TT genotypes were present in 38 (84.4\%), 5 (11.1\%), and 2 (4.4\%) of patients with CAD.

\section{The relationship between insulin sensitivity and eNOS genotype.}

All patients were divided into three groups: wild type (eNOS -786TT and eNOS 894GG), $\mathrm{T}^{-786} \rightarrow \mathrm{C}$ variant (eNOS -786TC/CC), and missense Glu298Asp variant (eNOS 894GT/TT). Table 2 summarizes the clinical characteristics of each group. No significant differences were observed between the three groups with respect to age, gender and a body mass index. The plasma immunoreactive insulin concentration at the 120 min time point (IRI 120) of a $75 \mathrm{~g}$ oral glucose tolerance test (75 g OGTT) was higher in the $\mathrm{T}^{-786} \rightarrow \mathrm{C}$ variant group (Table 2, $p<0.05$ ). A similar tendency was observed in the missense Glu298Asp variant group, but this difference was not significant.

\section{Discussion}

It has been recognized that the insulin resistance syndrome is one of the major predictors of atherosclerotic disease. The relationship between insulin resistance and cardiovascular risk, particularly the risk of coronary artery 
disease, has been well established in many prospective studies [17]. Insulin itself affects arterial smooth muscle cells, macrophages, and endothelial cells and may accelerate artherosclerosis [18]. Some studies have suggested that endothelium-dependent vasodilator function may be impaired in patients with atherosclerosis [19]. Furthermore, an association between endothelial nitric oxide production and insulin resistance has been reported [20].

In this study, we found a possible association between the $\mathrm{T}^{-786} \rightarrow \mathrm{C}$ eNOS gene polymorphism and insulin resistance. Furthermore, we hypothesize that low NO concentrations, caused by a defect in NO synthesis, may play a role. Experiments using transgenic eNOS knockout mice have confirmed that the absence of eNOS activity results in abnormal endothelium dependent vasodilation [21, 22] and accelerated atherosclerosis [23, 24]. Recent data show that eNOS knockout mice are insulin resistant, as evidenced by fasting hyperinsulinemia and decreased glucose infusion rates during euglycemic clamp studies [6]. These findings are thought to be mediated at the level of eNOS expressed in skeletal muscle tissue, where it may

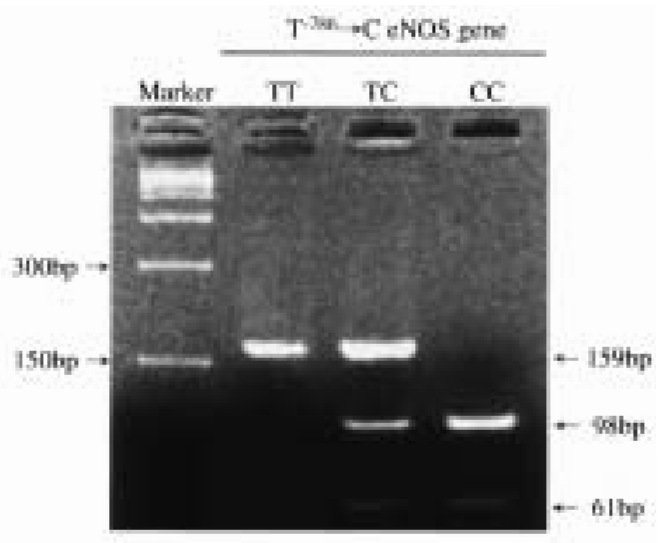

Fig. 1A. Use of PCR-RLFP analysis to screen for the $T^{-786} \rightarrow C$ mutation in the 5'-flanking region of the eNOS gene. Shown is a representative agarose gel loaded with wild type (TT), heterozygote (TC), and homozygote (CC) PCR product after digestion with Hae III, respectively. regulate insulin sensitivity [25].

The $\mathrm{T}^{-786} \rightarrow \mathrm{C}$ mutation has been reported to be associated with coronary spasm [12] and acute myocardial infarction in the absence of organic coronary artery stenosis [12]. It has been hypothesized that the $-786 \mathrm{~T} \rightarrow \mathrm{C}$ mutation suppresses eNOS gene transcription, reducing the production of endothelial $\mathrm{NO}$ and increasing vasoreactivity.

The incidences of the $\mathrm{T}^{-786} \rightarrow \mathrm{C}$ and Glu298Asp variants in patients with CAD were 30 to $70 \%[12,26]$, and 21.1 to $64 \%[7,8,16,26]$, respectively, in previous studies. Compared with these previous studies, the incidences in our study were lower (15.6\%, and $15.6 \%$, respectively, Table 2$)$. CAD represents a state of insulin resistance, and insulin resistance is considered a common factor for various atherogenic risk factors, including hypertension, glucose intolerance, and dyslipidemia. [27] Our patients represented a skewed group because of the influence of insulin resistance. That is why we could not find a positive association between the presence of the Glu298Asp variant and the development of CAD in the present study. Furthermore, our patient population was too small to iden-

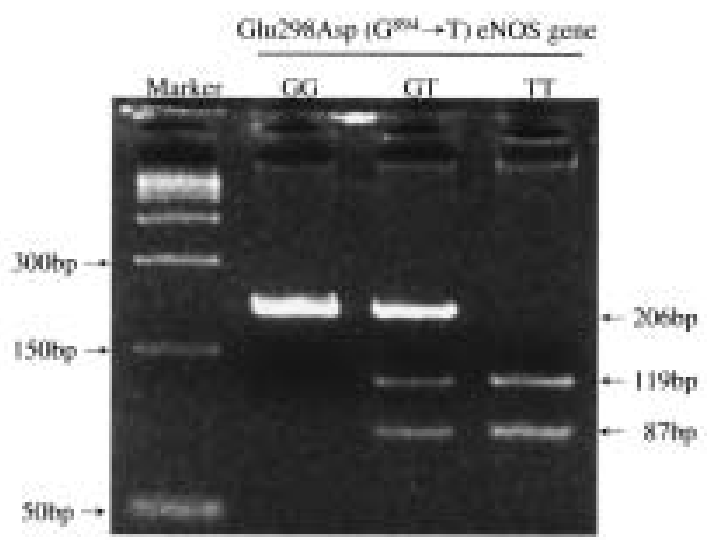

Fig. 1B. Use of PCR-RLFP analysis to screen for the missense Glu298Asp mutation at nucleotide position 894 of the eNOS gene in exon 7. Shown is a representative agarose gel loaded with wild type (GG), heterozygote (GT), and homozygote (TT) PCR product after digestion with Mbo I, respectively.

Table 2. Comparison of clinical characteristics

\begin{tabular}{lccc}
\hline & Wild type & $\mathrm{T}^{-786} \rightarrow$ C variant & Missense Glu298Asp variant \\
\hline Age $(\mathrm{y})$ & $62.3 \pm 10.6$ & $66.5 \pm 9.3$ & $61.3 \pm 6.1$ \\
Male/female & $23 / 8$ & $5 / 2$ & $5 / 2$ \\
$\mathrm{Ml} / \mathrm{AP} / \mathrm{spasm}$ & $18 / 8 / 5$ & $4 / 2 / 1$ & $4 / 2 / 1$ \\
$\mathrm{BMI}\left(\mathrm{kg} / \mathrm{m}^{2}\right)$ & $23.1 \pm 2.6$ & $23.6 \pm 3.1$ & $23.4 \pm 2.4$ \\
$\mathrm{IRl} 120(\mu / \mathrm{ml})$ & $55.8 \pm 31.25$ & $78.4 \pm 26.7^{*}$ & $69.6 \pm 38.4$ \\
\hline
\end{tabular}

$\mathrm{SI}$, insulin sensitivity index; IRI120, immunoreactive insulin concentration 120 min after $75 \mathrm{~g}$ OGTT. Data are reported as the mean \pm SD.

${ }^{*} p<0.05$ for variant vs. wild type. 
tify a statistically significant association.

Our data demonstrate the relationship between the $\mathrm{T}^{-786} \rightarrow \mathrm{C}$ eNOS polymorphism and insulin sensitivity. However, this tendency is not sufficient to conclude that the eNOS polymorphism is solely responsible for insulin resistance. These results demonstrate that insulin sensitivity is not affected by eNOS polymorphisms directly, but through changes in endothelial function and eNOS production in skeletal muscle.

In conclusion, the present study suggests that $\mathrm{T}^{-786} \rightarrow \mathrm{C}$ eNOS polymorphisms are associated with the development of insulin resistance.

Acknowledgments: We thank the staff of the cardiology division in Saga Medical school for their clinical assistance and suggestion.

\section{References}

(1) Radomski MW, Palmer RM, and Moncada S: Endogenous nitric oxide inhibits human platelet adhesion to vascular endothelium. Lancet, 2: 1057-1058, 1987

(2) Kubes P, Suzuki M, and Granger DN: Nitric oxide: an endogenous modulator of leukocyte adhesion. Proc Natl Acad Sci USA, 88: 4651-4655, 1991

(3) Sarkar R, Meinberg EG, Stanley JC, Gordon D, and Webb RC: Nitric oxide reversibly inhibits the migration of cultured vascular smooth muscle cells. Circ Res, 78: 225-230, 1996

(4) Garg UC and Hassid A: Nitric oxide-generating vasodilators and 8-bromocyclic guanosine monophosphate inhibit mitogenesis and proliferation of cultured rat vascular smooth muscle cells. J Clin Inves, 83: 1774-1777, 1989

( 5 ) Hogg N, Kalyanaraman B, Joseph J, Struck A, and Parthasarathy S: Inhibition of low-density lipoprotein oxidation by nitric oxide. FEBS Lett, 334: 170174, 1993

(6) Duplain H, Burcelin R, Sartori C, Cook S, Egli M, Lepori M, Vollenweider P, Pedrazzini T, Nicod P, Thorens B, and Scherrer U: Insulin resistance, hyperlipidemia, and hypertension in mice lacking endothelial nitric oxide synthase. Circulation, 104: 342345, 2001

( 7 ) Yoshimura M, Yasue H, Nakayama M, Shimasaki Y, Sumida $\mathrm{H}$, Sugiyama S, Kugiyama K, Ogawa $H$, Ogawa Y, Saito Y, Miyamoto Y, and Nakao K:A missense Glu298Asp varient in the endothelial nitric oxide synthase gene is associated with coronary spasm in the Japanese. Hum Genet, 103: 65-69, 1998

( 8 ) Shimasaki Y, Yasue H, Yoshimura M, Nakayama M, Kugiyama K, Ogawa $\mathrm{H}$, Harada E, Masuda T, Koyama W, Saito Y, Miyamoto Y, Ogawa Y, and
Nakao K: Association of the missense Glu 298 Asp varient of the endothelial nitric oxide synthase gene with myocardial infarction. J Am Coll Cardiol, 31: 1506-1510, 1998

(9) Hibi K, Ishigami T, Tamura K, Mizushima S, Nyui N, Fujita T, Ochiai H, Kosuge M, Watanabe Y, Yoshii Y, Kihara M, Kimura K, Ishii M, and Umemura S: Endothelial nitric oxide synthase gene polymorphism and acute myocardial infarction. Hypertension, 32: 521-526, 1998

(10) Lacolley P, Gautier S, Poirier O, Pannier B, Cambien $F$, and Benetos A: Nitric oxide synthase gene polymorphisms, blood pressure and aortic stiffness in normotensive and hypertensive subjects. J Hypertens, 16: 31-35, 1998

(11) Nakayama M, Yasue H, Yoshimura M, Shimasaki Y, Kugiyama K, Ogawa H, Motoyama T, Saito Y, Ogawa $\mathrm{Y}$, Miyamoto $\mathrm{Y}$, and Nakao K: T-786 $\rightarrow$ C mutation in the 5'-flanking region of the endothelial nitric oxide synthase gene is associated with coronary spasm. Circulation, 99: 2864-2870, 1999

(12) Nakayama $M$, Yasue $H$, Yoshimura $M$, Shimasaki $Y$, Kugiyama K, Ogawa $\mathrm{H}$, Kugiyama K, Mizuno $\mathrm{Y}$, Harada E, Nakamura S, Ito T, Saito Y, Miyamoto Y, Ogawa $\mathrm{Y}$, and Nakao K: T-786 $\rightarrow$ C mutation in the 5'-flanking region of the endothelial nitric oxide synthase gene is associated with myocardial infarction, especially without coronary organic stenosis. Am J Cardiol, 86: 628-634, 2000

(13) Nasreen S, Nabika T, Shibata H, Moriyama H, Yamashita K, Masuda J, and Kobayashi S: T-786 $\rightarrow$ C polymorphism in endothelial NO synthase gene affects cerebral circulation in smokers. Arteroscler Thromb Vasc Biol, 22: 605-610, 2002

(14) Despres JP, Lamarche B, Mauriege P, Cantin B, Dagenais GR, Moorjani $S$, and Lupien PJ: Hyperinsulinemia as an independent risk factor for ischemic heart disease. N Engl J Med, 334: 952957, 1996

(15) Suzuki M, Nishizaki M, Arita M, Kazuta T, and Numano F: Impaired glucose tolerance with late hypersecretion of insulin during oral glucose tolerance test in patients with vasospastic angina. J Am Coll Cardiol, 27: 1458-1463, 1996

(16) Hingorani AD, Liang CF, Fatibene J, Lyon A, Monteith S, Parsons A, Haydock S, Hopper RV, Stephens NG, O'Shaughnessy KM, and Brown MJ: A common variant of the endothelial nitric oxide synthase (Glu298 $\rightarrow$ Asp) is a major risk factor for coronary artery disease in the UK. Circulation, 100: 15151520, 1999

(17) Kannel WB: The Framingham Study: ITS 50-year legacy and future promise. J Atheroscler Thromb, 6(2): 60-66, 2000

(18) Stout RW: Insulin as a mitogenic factor: role in the 
pathogenesis of cardiovascular disease. Am J Med, 90: 62S-65S, 1991

(19) Egashira K, Inou T, Yamada A, Hirooka Y, and Takeshita A: Preserved endothelium-dependent vasodilation at the vasospastic site in patients with variant angina. J Clin Invest, 89: 1047-1052, 1992

(20) Petrie JR, Ueda S, Webb DJ, Elliott HL, and Connell JMC: Endothelial nitric oxide production and insulin sensitivity. Circulation, 93: 1331-1333, 1996

(21) Okumura K, Yasue H, Matsuyama K, Ogawa H, Kugiyama K, Ishizuka H, Sumida H, Fujii H, Matsunaga T, and Tsunoda R: Diffuse disorder of coronary artery vasomotility in patients with coronary spastic angina: hyperreactivity to the constrictor effects of acetylcholine and the dilator effects of nitroglycerin. J Am Coll Cardiol, 27: 45-52, 1996

(22) Faraci FM, Sigmund CD, Shesely EG, Maeda N, and Heistad DD: Responses of carotid artery in mice deficient in expression of the gene for endothelial NO synthase. Am J Physiol, 274: 564-570, 1998

(23) Chataigneau T, Feletou M, Huang PL, Fishman MC, Duhault J, and Vanhoutte PM: Acetylcholine-induced relaxation in blood vessels from endothelial nitric oxide synthase knockout mice. Br J Pharmacol, 126: 219-226, 1999

(24) Rudic RD, Shesely EG, Maeda N, Smithies O, Segal SS, and Sessa WC: Direct evidence for the importance of endothelium-derived nitric oxide in vascular remodeling. J Clin Invest, 101: 731-736, 1998

(25) Kapur S, Bedard S, Marcotte B, Cote CH, and Marette A: Expression of nitric oxide synthase in skeletal muscle. Diabetes, 46: 1691-1700, 1997

(26) Fatini C, Gensini F, Sticchi E, Battaglini B, Angotti C, Conforti ML, Generini S, Pignone A, Abbate R, and Matucci-Cerinic M: High prevalence of polymorphisms of angiotensin-converting enzyme (I/D) and endothelial nitric oxide synthase (Glu298Asp) in patients with systemic sclerosis. Am J Med, 112: 540544, 2002

(27) Cullen P, Funke H, Schulte H, and Assmann G: Lipoprotein and cardiovascular risk-from genetics to CHD prevention. J Atheroscler Thromb, 4 (2): 5158, 1997 